\title{
Modeling-impact of Land Use/Cover Change on Sediment Yield (Case Study on Omo-gibe Basin, Gilgel Gibe III Watershed, Ethiopia)
}

\author{
Tesfaye Hailu Estifanos ${ }^{1}$, , Bogale Gebremariam ${ }^{2}$ \\ ${ }^{1}$ Department of Natural Resource Management, Wolaita Sodo University, Wolaita Sodo, Ethiopia \\ ${ }^{2}$ Department of Hydraulic and Water Resource Engineering, Arbaminch University, Arbaminch, Ethiopia
}

Email address:

tesfaw74@gmail.com (T. H. Estifanos)

*Corresponding author

\section{To cite this article:}

Tesfaye Hailu Estifanos, Bogale Gebremariam. Modeling-impact of Land Use/Cover Change on Sediment Yield (Case Study on Omo-gibe Basin, Gilgel Gibe III Watershed, Ethiopia). American Journal of Modern Energy. Vol. 5, No. 6, 2019, pp. 84-93.

doi: 10.11648/j.ajme.20190506.11

Received: November 30, 2019; Accepted: December 26, 2019; Published: January 8, 2020

\begin{abstract}
Impacts of land use/cover change on water resources are the result of complex interactions between diverse sitespecific factors and offsite conditions; standardized types of responses will rarely be adequate. The knowledge of how land use/cover change influence watershed hydrology will enable local governments and policy makers to formulate and implement effective and appropriate response strategies to minimize the undesirable effects of future land use/cover change or modifications. In this research SWAT model was used for analyzing the land use and land cover change of the watershed and its impact on reservoir sedimentation. The main objective of the research was to model the hydrological processes that will predict the impact of land use/cover changes on soil erosion and sedimentation in the Omo-gibe basin. In this paper the influence of land use changes on catchment's sediment yield is observed. The delineated watershed was divided into 62 sub basins and 372 HRUs by the model. Model calibration and validation was done at Abelti station. In addition to this the model efficiency was checked at this station. Based on this values for coefficient of determination $\left(r^{2}\right)$, Nash-Sutcliffe model efficiency (NSE) and percentage of bias (PBIAS) were found to be in the acceptable range for 1990 and 2010 land use land cover maps in both calibration and validation period. To analyze the impact of land use change on sediment yield different comparison criteria were applied. The first was selecting sub basins having higher sediment yield and found around the main course of the river. The second was selecting and analyzing sub basins having lower sediment yield and the third criterion was based on availability of varied land use classes specially sub basins covered by forest land. While analyzing the impact of land use/cover in all criteria using 1990 and 2010 land use/cover map, it shows an increase in sediment yield. SWAT estimated the sediment yield from the watershed to the reservoir for both 1990 and 2010 land use/cover maps. Therefore $1.1 \mathrm{M}$ tons annual sediment load was entered to the reservoir during 1990 and $1.3 \mathrm{M}$ tons annual sediment load was entered to the reservoir during 2010 land use/cover data. This shows that there is $16.57 \%$ increment of sediment yield in 2010 as compared to 1990 land use/cover data.
\end{abstract}

Keywords: Land Use/Land Cover, Omo-gibe Basin, SWAT, Sedimentation, Calibration, Validation

\section{Introduction}

Land use change is ubiquitous drivers of global environmental change. Impact assessments frequently show that interactions between climate and land use change can create serious challenges for aquatic ecosystems, water quality, and air. For instance, the changes in land-cover have affected the surface and groundwater hydrology and altering the hydrological cycle $[23,24]$. These effects vary as functions of seasonality and the changing climate [20]. Hence, it might be appropriate to analyze land use/land cover and crucial to know the effects of land use change on catchment hydrology for sound land use planning and water resource management. 
The knowledge how land use/cover change influence watershed hydrology will enable local governments and policy makers to formulate and implement effective and appropriate response strategies to minimize the undesirable effects of future land use/cover change or modifications. Given that impacts of land use/cover change on water resources are the result of complex interactions between diverse site-specific factors and offsite conditions, standardized types of responses will rarely be adequate. General statements about land-water interactions need to be continuously questioned to determine whether they represent the best available information and whose interests they support in decision-making processes [12]. Land and water resources degradation are the major problems in the Ethiopian highlands. Poor land use practices and improper management systems have played a significant role in causing high soil erosion rates, sediment transport and loss of agricultural nutrients. So far limited measures have been taken to combat the problems. In this study a physically based watershed model, SWAT will be applied to the Omo basin of Ethiopia for modeling of the hydrology and sediment yield. The main objective of this study will be to test the performance and feasibility of SWAT model to examine the influence of land use/cover changes on sediment yield. Ethiopia experiences persistent land, water and environmental degradation due to localized and global climatic anomalies. These leave the country to recurrent crop failures and severe food shortages. Low soil fertility coupled with temporal imbalance in the distribution of rainfall and the substantial non-availability of the required water at the required period are the principal contributing factors to the low and declining agricultural productivity. Hence, proper utilization of the available soil and water resources is essential to Ethiopia's agricultural development and achievement of food security.

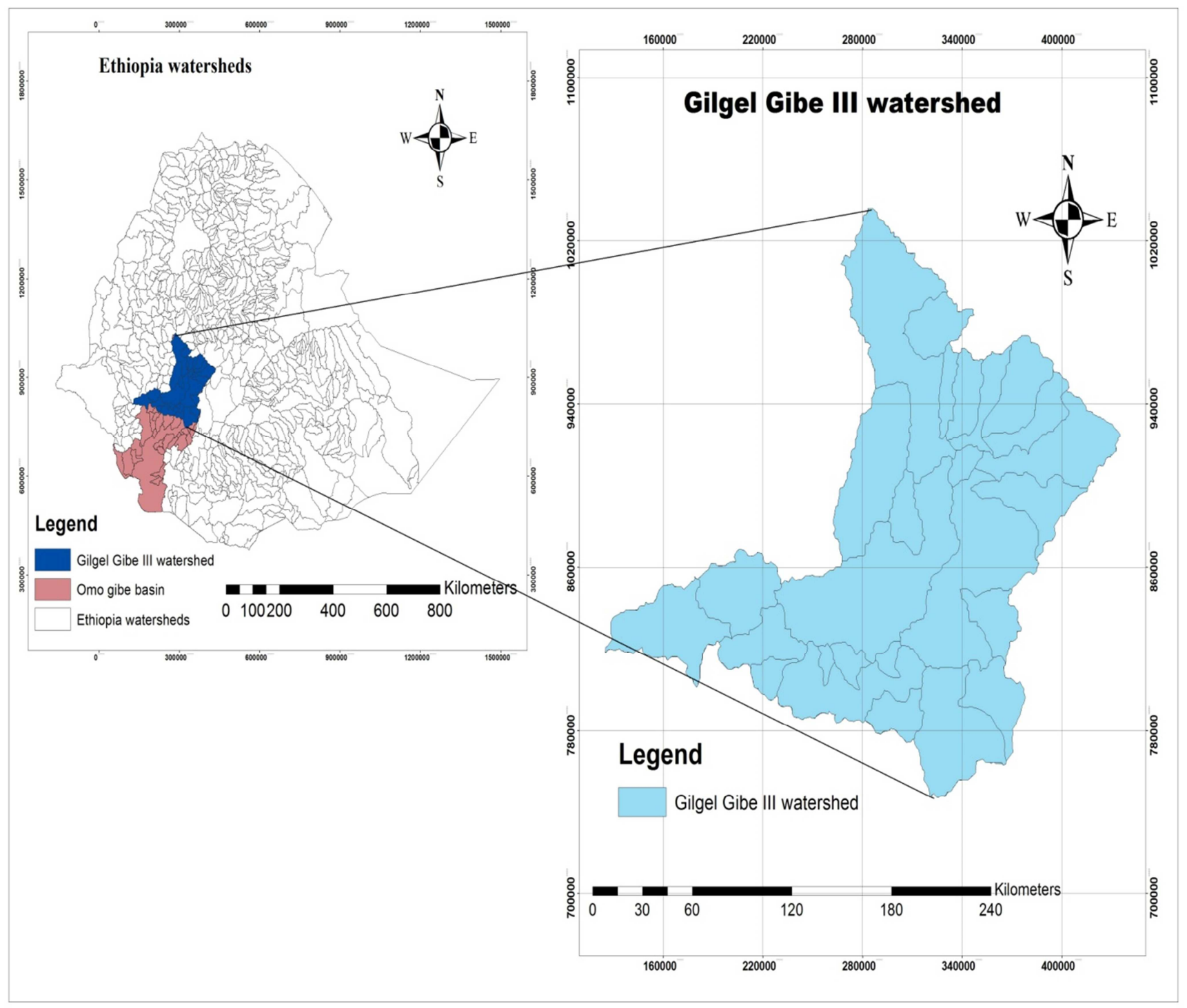

Figure 1. Location map of the study area (Gilgel gibe III watershed).

The Omo-Gibe River Basin is almost $79,000 \mathrm{~km}^{2}$ in area and is situated in the south-west of Ethiopia, between $4^{\circ} 00^{\prime} \mathrm{NAnd} 9^{\circ} 22^{\prime} \mathrm{N}$ latitude and between $34^{\circ} 44^{\prime} \mathrm{E} \& 38^{\circ} 24^{\prime} \mathrm{E}$ longitude. It is an enclosed river basin that flows in to the 
Lake Turkana in Kenya which forms its southern boundary. The western watershed is the range of hills and mountains that separate the Omo-Gibe Basin from the Baro-Akobo Basin. To the north and northwest the basin is bounded by the Blue-Nile Basin with small area in the northeast bordering the Awash Basin. The gibe III catchment is also found in the upper part of Omo-gibe basin which covers an area of some $400 \mathrm{~km}$ South West of Addis Ababa and $150 \mathrm{~km}$ west-Southwest of Hawassa. The project is located within the jurisdiction of the Mareka Gana Wereda of the Dawro Zone and Kindo Koyisha Wereda of Sodo zone of the Southern Nations and Nationalities People Regional State (SNNPRS).

Water erosion is a major part of land degradation in the study catchment that affects the physical and chemicalproperties of soils and resulting in on-site nutrient loss and off-site sedimentation of water resources. The offsiteeffects of erosion such as reservoir sedimentation and water resources pollution are usually more costly and severethan the on-site effects on land resources [22]. Therefore, proper management of on-site effect of soil erosion couldreduce the risks and negative impacts of downstream water resources due to water erosion.

Thus, this study was conducted to determine the effects of land use patterns on soil erosion and sediment yield in the basin using the SWAT model. Specifically, the objectives were to parameterize, calibrate and use the SWAT model in simulating the effects of land use change on soil erosion and sediment yields and compare different alternatives (scenario) and finally to choose the appropriate/solution.

\section{Materials and Methods}

\subsection{Data Sources}

The followings are the sources where the data has been collected:

Table 1. sources of data.

\begin{tabular}{lll}
\hline no & Data type & Source of data \\
\hline 1 & Meteorological data & Ethiopian meteorological agency \\
2 & Hydrological data & Ethiopian Ministry of water and energy \\
3 & Digital Elevation & www.usgs.org (online source) \\
4 & Model (DEM) & Land use/cover map \\
5 & Soil map & FAO soil (online source) \\
6 & Sediment data & Gilgel Gibe III dam project office \\
\hline
\end{tabular}

\subsection{Data Type}

The following data were used to conduct the research:

i. DEM (Digital Elevation Model)

Digital elevation model (DEM) of Gilgel gibe III watershed (Figure 2) was used as a model input for SWAT. It was having a resolution of $90 \mathrm{~m} \times 90 \mathrm{~m}$. It is one of the spatial inputs of SWAT model for delineating the watershed from the Omo-gibe basin and it was obtained from ministry of water (MoWR).



Figure 2. Digital elevation model of Gilgel- gibe III watershed. 
ii. Soil map and land use/cover maps

Land use/cover data were taken for different times for scenario development and to see the change. 1990s and 2010s (Figure 3) land use/cover data were used to study the impact of land use change on sedimentation for the study area.


Figure 3. Land use/cover maps of the study area (1990s and 2010s).



Figure 4. Soil map of the study area.

Spatial data projection

All spatial data sets were projected to UTM 37 North and D_WGS_1984 datum. Re projections were done using Arc GIS 9.3's raster and vector standard world re project tools. Arc SWAT requires all data to be in the same projection before any GIS processing can take place. The UTM projection was chosen as it is commonly used for larger areas in GIS.

iii. Flow data

Monthly flow data of Great Gibe near Abelti of years 1996-2008 was used for calibration and validation of thesimulated flow. The reason this gauging station considered was that this is the biggest contributor of the river flow of the watershed above the dam; plus it is situated on the main route of the river. The flow data were obtained fromMinistry of Water Resources. Missing data of Abelti station was filled using the following correlation of nearbygauging stations in the gibe water shed.

iv. Weather data

SWAT requires daily meteorological data that could either be read from a measured data set or be generated by a weather generator model. In this study, the weather variables used for driving the hydrological balance are daily precipitation, minimum and maximum air temperature, relative humidity, wind speed, and daily sunshine hours for the period 1990-2010. These data were obtained from Ethiopian National Meteorological Agency (NMA) for stations in and around the water shed. The following stations were used for analyzing the weather data in the catchment: 
Table 2. Location of meteorological stations within and around the watershed.

\begin{tabular}{llll}
\hline Station name & Latitude (degree) & Longitude (degree) & Elevation $(\mathbf{m})$ \\
\hline ABELTI & 8.10 & 37.32 & 2050 \\
ANGACHA & 7.34 & 37.86 & 2317 \\
ASENDABO & 7.75 & 37.22 & 1764 \\
BODITY & 6.95 & 37.96 & 2043 \\
IMDIBIR & 8.12 & 37.94 & 1867 \\
JIMA & 7.67 & 36.82 & 1718 \\
SHEBE & 7.50 & 36.52 & 1813 \\
SHISHINDA & 7.25 & 36.88 & 2000 \\
WOLKITE & 8.13 & 37.45 & 1550 \\
WOLISO & 8.41 & 38.23 & 2000 \\
YEBU & 7.68 & 36.82 & 1950 \\
HOSANA & 7.33 & 37.52 & 2200 \\
LIMU GENET & 8.07 & 36.95 & 1766 \\
BUEI & 8.24 & 38.06 & 1960 \\
\hline
\end{tabular}

From the above listed meteorological stations only two stations have all type of data important for SWAT input but others have only rain fall and temperature data. i.e. Hosanna and Welkite stations have all data (synoptic stations). These two stations were used as weather generating stations for others. Their location can be illustrated in the figure below.

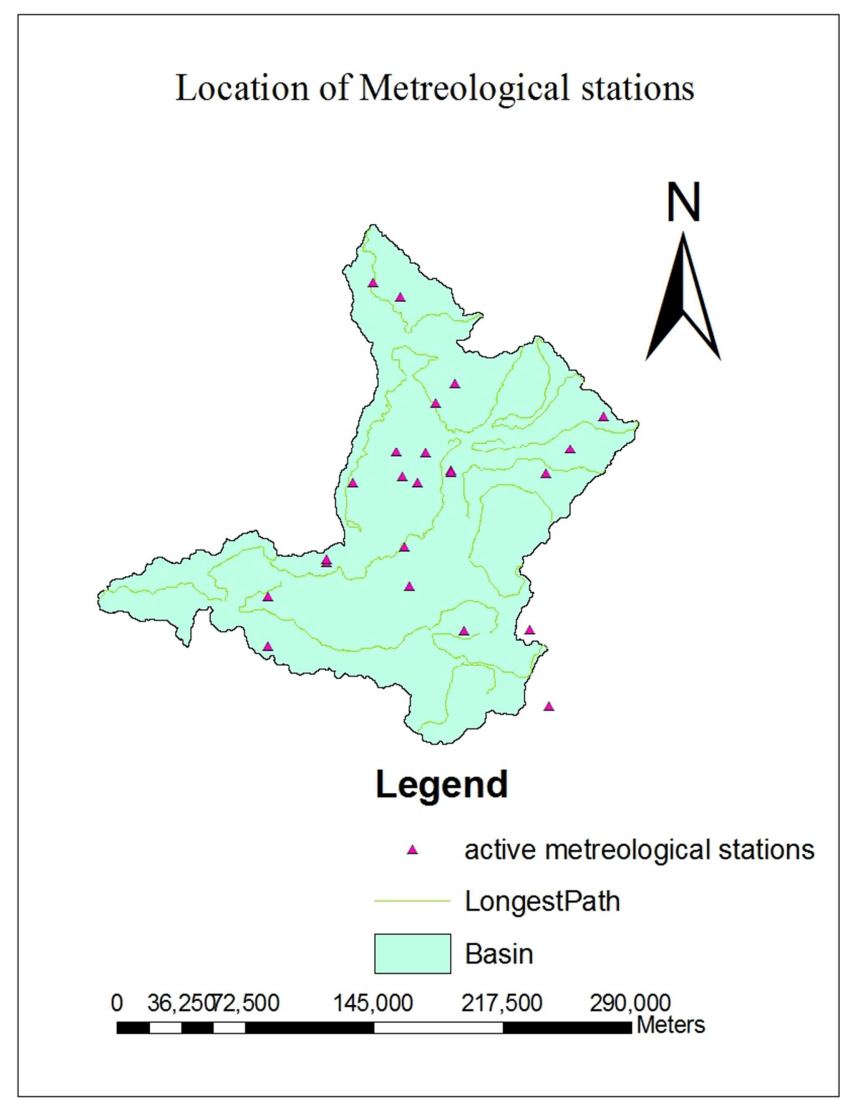

Figure 5. Location of meteorological stations.

\section{Result and Discussion}

\subsection{Sensitivity Analysis for Flow and Sediment Yield}

Table 3. Selected sensitive parameters of flow in Gilgel gibe-III watershed.

\begin{tabular}{llllll}
\hline Rank & parameter & $\begin{array}{l}\text { Lower } \\
\text { bound }\end{array}$ & $\begin{array}{l}\text { Upper } \\
\text { bound }\end{array}$ & $\begin{array}{l}\text { Mean } \\
\text { sensitivity }\end{array}$ & $\begin{array}{l}\text { Degree of } \\
\text { sensitivity }\end{array}$ \\
\hline 1 & Alpha_Bf & 0 & 1 & 1.18 & Very high \\
2 & Cn2 & 35 & 98 & 0.585 & High \\
3 & Esco & 0 & 1 & 0.316 & High \\
4 & Sol_Z & 0 & 3000 & 0.309 & High \\
5 & Gwqmn & 0 & 5000 & 0.227 & High \\
6 & Revapmn & 0 & 500 & 0.152 & Medium \\
7 & Sol_Awc & 0 & 1 & 0.122 & Medium \\
8 & Gw_Delay & 0 & 50 & 0.0963 & Medium \\
9 & Blai & 0 & 1 & 0.0916 & Medium \\
10 & Gw_Revap & 0.02 & 0.2 & 0.0779 & Medium \\
\hline
\end{tabular}

Similarly sensitivity analysis was done for sediment yield calibration and validation. Sensitive parameters for sediment yield in the watershed includes USLE support practice factor (USLE_ P), linear factor for channel sediment routing (SPCON), exponential factor for channel sediment routing (SPEXP) and USLE cover or management factor (USLE_C) were found very high to high sensitive to sediment flow. From those sensitive parameters USLE support practice factor (USLE_P) was the most sensitive of all (Table 4).

Table 4. Selected sensitive parameters of sediment in Gilgel gibe-III watershed.

\begin{tabular}{llllll}
\hline Rank & parameters & $\begin{array}{l}\text { Lower } \\
\text { bound }\end{array}$ & $\begin{array}{l}\text { Upper } \\
\text { bound }\end{array}$ & $\begin{array}{l}\text { Mean sensitivity } \\
\text { index }\end{array}$ & $\begin{array}{l}\text { Category of } \\
\text { sensitivity }\end{array}$ \\
\hline 1 & Usle_P & 0 & 1 & 5.60 & Very high \\
2 & Spcon & 0.0001 & 0.01 & 1.55 & High \\
3 & Spexp & 1 & 2 & 0.094 & High \\
4 & Usle_C & -25 & 25 & 0.051 & High \\
\hline
\end{tabular}

\subsection{Flow Calibration and Validation}

Table 5. Default and final calibrated flow parameter values of the watershed.

\begin{tabular}{llll}
\hline parameter & range & Initial/default value & Adjusted value \\
\hline Alpha_Bf & $0-1$ & 0.048 & 0.094 \\
Cn2 & $25 \%$ & $45-82$ & $+20 \%$ \\
Esco & $0-1$ & 1 & 0.9 \\
Gwqmn & $0-5000$ & 0 & 4500 \\
Sol_Awc & $\pm 25 \%$ & $18-30$ & $+18 \%$ \\
\hline
\end{tabular}

As it is shown in the above table the adjusted value for threshold depth of water in the shallow aquifer required forreturn flow to occur (GWQMN) seems higher. When the value for GWQMN is replaced by a value less than 4500 theperformance of the SWAT model would lie in unacceptable range or in other word the model performance would bepoor. For instance when the value for GWQMN is replaced by 4000 , the performance parameters of SWAT model $\left(\mathrm{R}^{2}\right.$, NSE and PBIAS would be $0.62,0.51$ and $19 \%$ respectively) will be poor. 


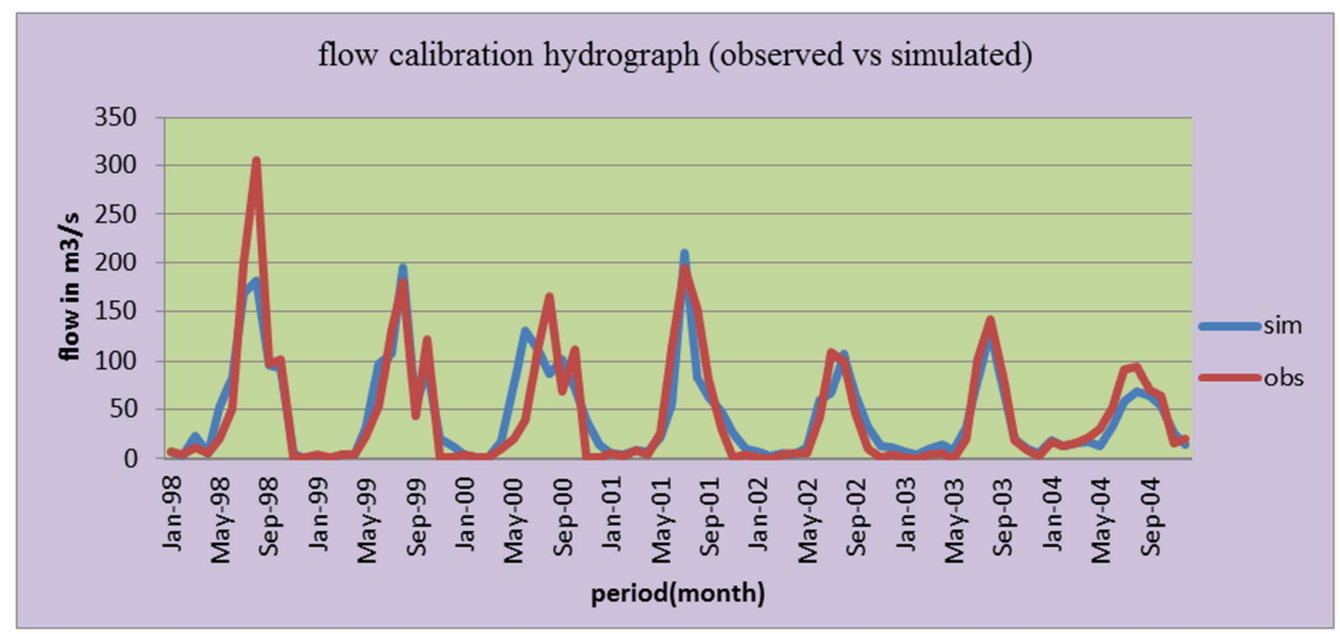

Figure 6. Flow calibration hydrograph.

The hydrograph of the calibration period of the observed and simulated flow shows, the model slightly overestimate some of monthly peak flows of the years; such as August 1999, July of 2001 and also slightly underestimate the peak flows, like August of 1998 and 2000, August of 2003 and July of 2002 and 2004 of the year's monthly mean flows. Low and medium flows were relatively estimated well by the model.

Likewise, flow validation of the model for the watershed was carried out from January 1, 2005 to December 31, 2008. Therefore, for the model performance in validation period was considered from 2005 to 2008, without further adjustment of the parameters of flows. The objective functions that used for evaluation were in the acceptance range for the validation time of the model in monthly time step and the $\mathrm{r}^{2}$, NSE and PBIAS indicates $0.85,0.84$ and $-5.6 \%$ respectively.

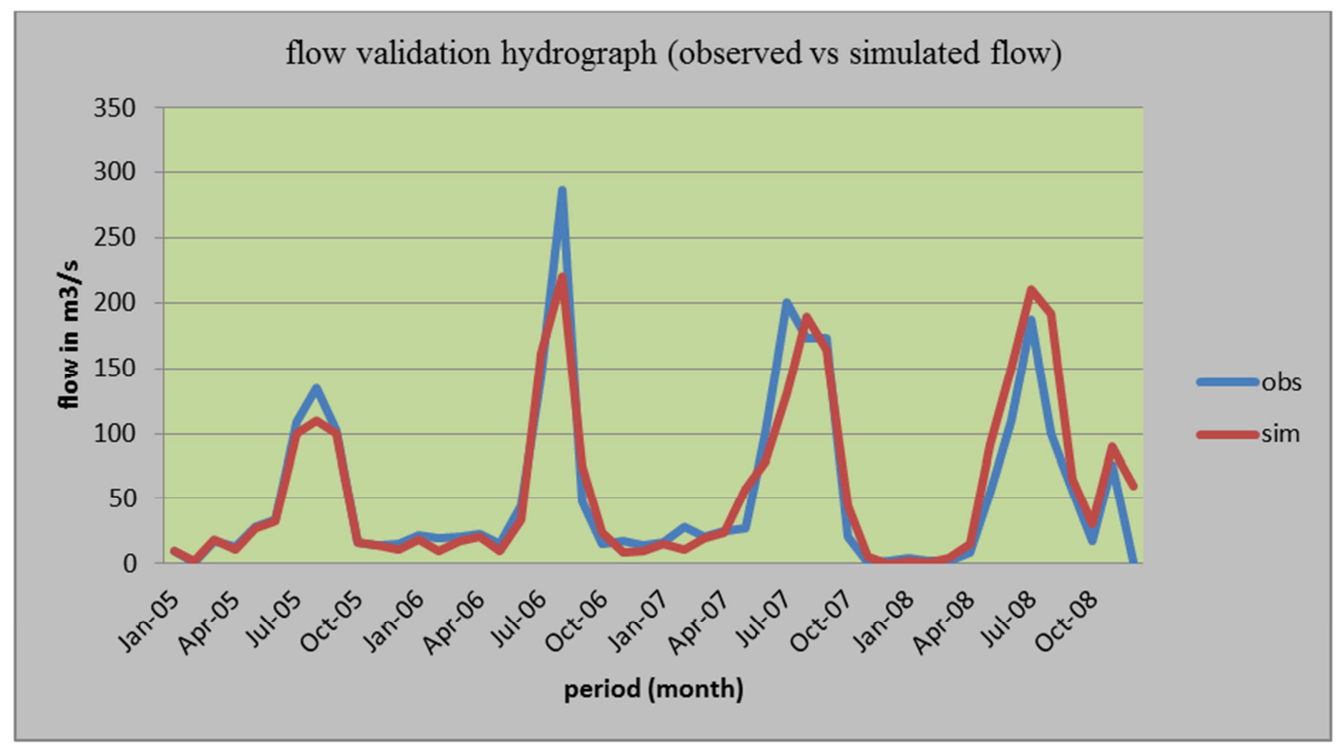

Figure 7. Flow validation hydrograph.

The hydrograph of the validation period of the observed and simulated flow in monthly estimation, the model under estimates some of the peak flows of the months, like August of the year 2005 and 2006 and also August and September of the year 2007. Some of the months peak flows were also overestimated by the model such as July, August, September and November of the 2008. Some of the medium and low flows were underestimated and over estimated by the model with in the years.

Table 6. Calibration and validation statistics of simulated and gauged monthly flows at Abelti gauging station.

\begin{tabular}{|c|c|c|c|c|c|c|c|}
\hline \multirow{2}{*}{ simulation } & \multicolumn{2}{|c|}{ Total flow $\left(\mathrm{m}^{3} / \mathrm{s}\right)$} & \multicolumn{2}{|c|}{ Mean annual flow $\left(\mathrm{m}^{3} / \mathrm{s}\right)$} & \multicolumn{3}{|c|}{ Model performance evaluation } \\
\hline & observed & simulated & observed & simulated & $r^{2}$ & NSE & PBIAS \\
\hline Calibration (1998-2004) & 3750.483 & 3702.124 & 44.649 & 44.073 & 0.80 & 0.79 & 1.29 \\
\hline Validation (2005-2008) & 2564.083 & 2707.763 & 53.418 & 56.412 & 0.85 & 0.84 & -5.6 \\
\hline
\end{tabular}




\subsection{Sediment Calibration and Validation}

The observed and simulated sediment load in the calibration period shows the model slightly overestimated some of monthly sediment yields of the watershed such as
June of 2000 and august of 2001 and slightly under estimate the sediment yield of august of 1998 and 2003 July of the years 2002 and 2004 (Figure 8). The model is slightly good in estimating the sediment yield of medium sediment loads.



Figure 8. Sediment calibration graph.

Table 7. Default and final sediment calibration parameter values of the watershed.

\begin{tabular}{lllll}
\hline parameters & Range & $\begin{array}{l}\text { default } \\
\text { value }\end{array}$ & $\begin{array}{l}\text { Adjusted } \\
\text { values }\end{array}$ \\
\hline Usle_P & & $0-1$ & 1 & 0.75 \\
Spcon & & $0.0001-0.01$ & 0.0001 & 0.0089 \\
Spexp & & $1-2$ & 1 & 1.47 \\
& For agricultural land & $0.001-0.5$ & 0.03 & 0.4 \\
Usle_C & For forest & $0.001-0.5$ & 0.003 & 0.1 \\
& For range grass & $0.001-0.5$ & 0.03 & 0.35 \\
& For range brush & $0.001-0.5$ & 0.05 & 0.25 \\
\hline
\end{tabular}

Validation of sediment yield of the watershed was carried out with the same manner as flow validation. It was done for four years from January 1, 2005 to December 31, 2008. Therefore, for the model performance in validation was considered from 2005 to 2008 without further adjustment of the parameters. The statistical values sediment yield estimation in the validation period results the $\mathrm{r}^{2}$, NSE and PBIAS were $0.87,0.86$ and $2 \%$ respectively (Table 7 ). These values are in the acceptable range, so the model estimation is good.

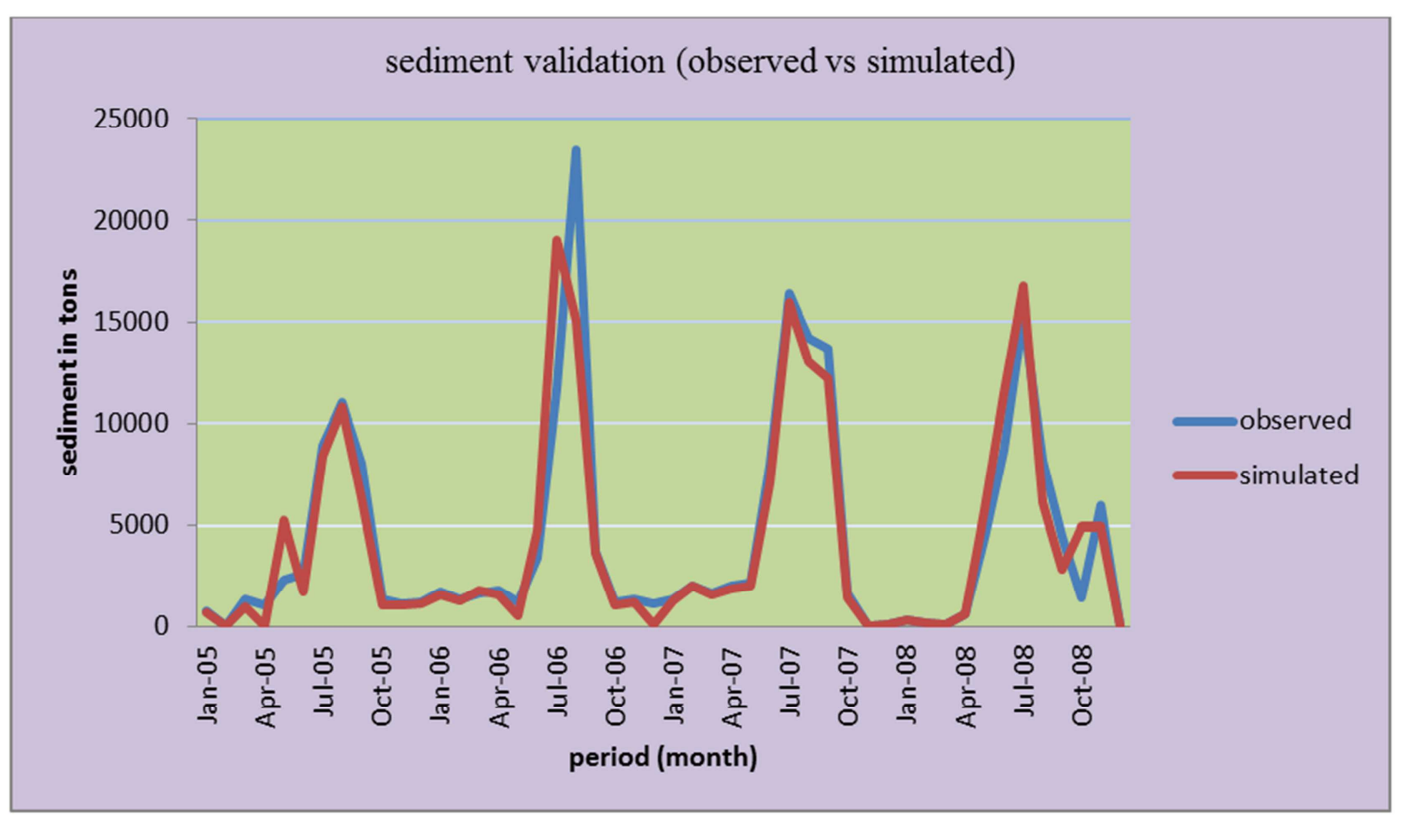

Figure 9. Sediment validation graph. 

Yield (Case Study on Omo-gibe Basin, Gilgel Gibe III Watershed, Ethiopia)

Table 8. Calibration and validation statistics of simulated and gauged monthly sediment load.

\begin{tabular}{|c|c|c|c|c|c|}
\hline \multirow{2}{*}{ Monthly time step } & \multirow{2}{*}{ Period of time or duration } & \multicolumn{4}{|c|}{ Model performance } \\
\hline & & $r^{2}$ & NSE & PBIAS & remarks \\
\hline Calibration & $1998-2004$ & 0.83 & 0.82 & $3 \%$ & acceptable \\
\hline Validation & $2005-2008$ & 0.87 & 0.86 & $2 \%$ & acceptable \\
\hline
\end{tabular}

\subsection{Analysis of Land Use/Cover Change}

It is clearly shown that there is a significant change of LULC from 1990 land use map to 2010 land use map. The agricultural land for 1990 LULC map was $46.2 \%$ and increased by $25.23 \%$ and become $71.43 \%$ for 2010 LULC map. But shrub land was decreased by $19.06 \%$ from 1990 to 2010. forest land also decreased from 7.91\% (1990 LULC map) to $0.66 \%$ (2010 LULC map).

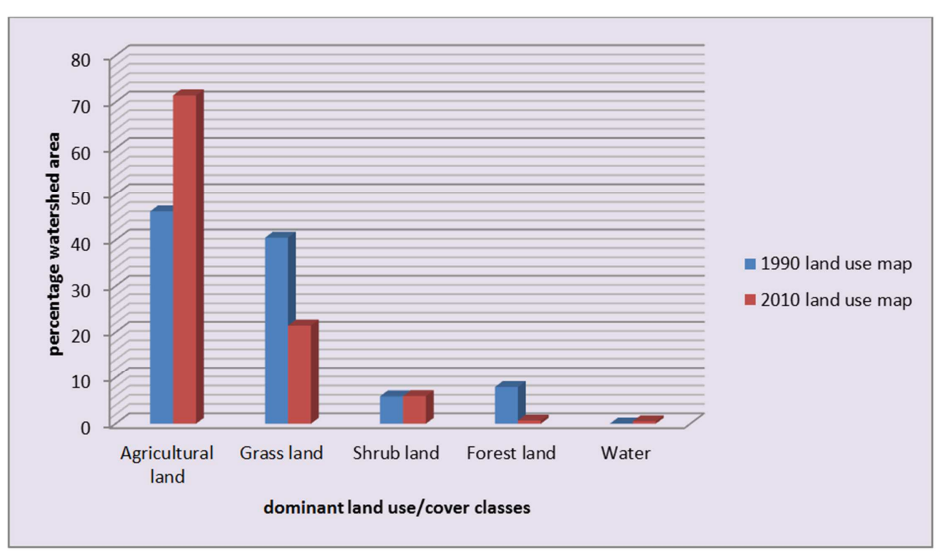

Figure 10. Dominant land use/cover classes of 1990s and 2010s.

\subsection{Comparing Sediment Yield Estimation}

SWAT has classified the watershed in to 62 sub basins. From theses sub basins ten of them were selected based on sediment yield (higher and lower) and forest coverage.



Figure 11. Mean annual sediment yield (ton/ha) for selected sub basins.

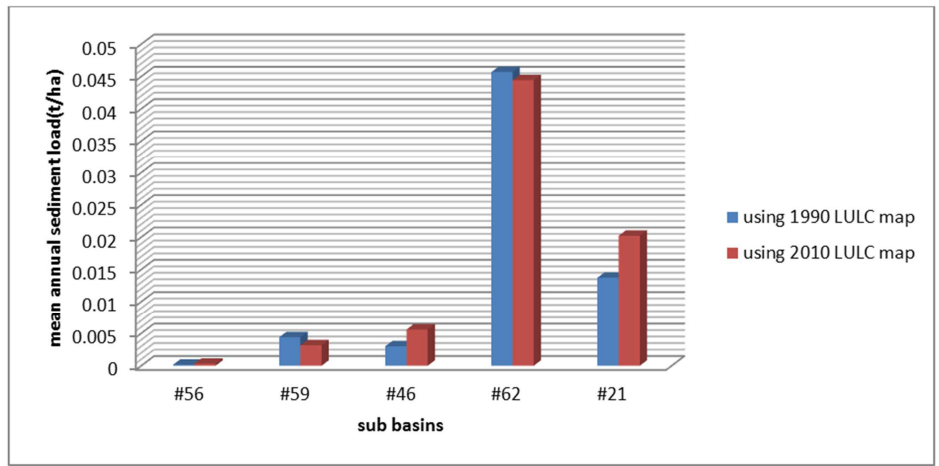

Figure 12. Mean annual sediment yield of sub basins based on forest coverage. 
Based on the first criterion shown above, the result shows that there is an increase in sediment yield in all selected sub basins. This was due to increase in agricultural land and decrease in forest land. Based on the second criterion those sub basins having lowest sediment yield has made a very small change in sediment yield. sub basins 56,46 and 21 are showing an increase in sediment yield from 1990 to 2010 . But sub basins 59 and 62 are showing decrease in sediment yield. Since sub basin 62 is found at the out let of the watershed around the reservoir, watershed management practice is made to decrease the sediment yield by the Gilgel gibe 3 dam project.

Sub basins 56, 46 and 21 are showing an increase in sediment yield from 1990 to 2010 . But sub basins 59 and 62 are showing decrease in sediment yield.

\section{Conclusion}

The SWAT model was found to be useful in identifying effect of land use changes on hydrological properties and sediment yield. SWAT model performance in the Gilgel gibe III Catchment was very good in predicting sediment load despite scarce data of observed suspended sediment load.

As it is looked from the model performance efficiency indicators, regression coefficient $\left(\mathrm{r}^{2}\right)$, the Nash-Sutcliffe (NSE) and percentage of bias (PBIAS) are found to be 0.80 , 0.79 and $1.29 \%$ respectively in calibration and $0.85,0.84$ and - 5.6 respectively in validations for flow analysis. Similarly, sediment model efficiency indicators $\mathrm{r}^{2}$, NSE and PBIAS are found to be $0.83,0.82$ and $3 \%$ for calibration and $0.87,0.86$ and $2 \%$ in validation respectively. This shows that, the SWAT model simulates well both for stream flow and sediment yield/load in the Gilgel gibe III catchment.

Simulation result indicates that land use/land cover change has a great impact on reservoir sedimentation. To analyze the impact of land use change on sediment yield different comparison criteria were applied. The first was selecting sub basins having higher sediment yield and found around the main course of the river and the second was selecting and analyzing sub basins having lower sediment yield and the third criterion was based on availability of varied land use classes specially sub basins covered by forest land. While analyzing the impact of land use/cover in all criteria using 1990 and 2010 land use/cover map, it shows that an increase in sediment yield.

SWAT was estimated the sediment yield from the watershed to the reservoir for both 1990 and 2010 land use/cover maps. Therefore 1.1Mtone annual sediment load was entered to the reservoir during 1990 and 1.3Mtone annual sediment load was entered to the reservoir during 2010 land use/cover data. Then it shows that there is $16.57 \%$ increment of sediment yield in 2010 as compared to 1990 land use/cover data.

The high soil loss rate in the catchment can be attributed to the deforested lands, the poor land cover, the shallow soil depth, and high rainfall intensity. The SWAT model also had the capability to identify areas within a watershed with high erosion and sediment yield. This helps to prioritize and formulate development and conservation plans in order to use available economic resources optimally. Since the erosion process occurred in the watershed is believed to be the major source of sediment load, it is important to give due attention for appropriate watershed development or soil and water conservation at least for those places which are major causes for higher sediment yield.

\section{References}

[1] Abdela Kemal, (2007). Developing of flood warning and forecasting system for Omo gibe river basin, MSc thesis, Arba-Minch University.

[2] Arnold, J. G., Williams, J. R., and Maidment, D. R., (1995). Continuous-time water and sediment routing model for large basins.

[3] Arnold, J. G., R. S. Muttiah, R. Srinivasan, and P. M. Allen, (2000). Regional Estimating of Base flow and Groundwater Recharge in the Mississippi River Basin. Journal of Hydrology, $227,21-40$.

[4] Arnold JG, Srinivasan R, Muttiah RR, Williams JR. (1998). Large Area Hydrologic Modeling and Assessment Part I: Model Development. Journal of the American Water Resources Association; 34 (1): 73-89.

[5] Constable, m. (1985). Ethiopian Highland Reclamation Study (EHRS): Summary. EHRS: Addis Ababa.

[6] Cunderlik M., (2003). Hydrologic model selection fort the CFCAS project: Assessment of Water Resources Risk and Vulnerability to Changing Climatic Conditions, Project Report I, $40 \mathrm{pp}$.

[7] DeCoursey, D. G., (1985). Mathematical models for point sources water pollution control. J. Soil and Water Cons. 44 (2): 568-576.

[8] Daniel Assefa, (2011). Water Use and Operation Analysis of Water Resource Systems in Omo Gibe River Basin, MSc thesis, Arbaminch University.

[9] Dramis, f., umer Mohammed, Calderon, g., mitiKu Haile. (2003). Holocene climatephases from buried soils in Tigray (northern Ethiopia): Comparison with lake level fluctuations in the main Ethiopian Rift. Quaternary Research: pp. 274-283.

[10] EEPCO, Gilgel Gibe III HPP Project (2007) ì RCC- Dam Alternative 3 power house on the left River Bank. Studio Pietrangeli ñ Salini Construction.

[11] Food and Agricultural Organization (FAO), (1998). The Soil and Terrain Database for northeastern Africa (CDROM) FAO, Rome.

[12] FAO (2002) Food and Agriculture Organization of the United Nations Viale delle Terme di Caracalla, 00100 Rome, Italy.

[13] Gete Zeleke. 2000. Landscape dynamics and soil erosion process modeling in the northwestern Ethiopian Highlands. $\mathrm{PhD}$ thesis. African Studies A16. Geographical Bernensia. CDE, University of Bern, Bern. 
[14] GLASOD. (1990). World Map of the Statusof Human-Induced Soil Degradation. United Nations Environment Programme (UNEP) and International Soil Reference Information Centre (ISRIC), Nairobi and Wageningen.

[15] Hargreaves GL, Hargreaves GH, Riley JP. (1985). Agricultural benefits for Senegal River basin irrigation And Drainage Engineering; 111 (2): 113-124.

[16] Hudson, (1995). Soil conservation. $3^{\text {rd }}$ edition. Bats ford, London.

[17] Hurni, h. (1988a). Ecological Issues in the Creation of Famines in Ethiopia. National Conferenceon a Disaster Prevention \& Preparedness Strategy of Ethiopia. Addis Ababa.

[18] Hurni, h. (1988b). Principles of soil conservation for cultivated land. Soil Technology. Vol. 1: pp. 101-116.
[19] Hurni, h. (1982). Soil Conservation Research Project, Inception report: 55 p. Bern, Addis Ababa.

[20] Huxman, et al, (2005). Eco hydrological implications of woody plant encroachment. Ecology 86, 308-319.

[21] Lal, r. 1995. Erosion - Crop Productivity Relationships for Soils in Africa. Soil Science Society of America Journal 59 (3): pp. 661-667.

[22] Philips, (1989), Methodology and application of combined watershed and ground water models in Kansas. J. Hydrol. 236 (3-4): 185-201.

[23] Skaggs, R. W., D. M. Amatya, G. M. Chescheir, C. D. Blanton, and J. W. Gilliam. (2006). Effects of drainage and management practices on hydrology of pine plantation. In Proc. Intl. Conf. on Hydrology and Management of Forested Wetlands, St. Joseph, Mich.: ASABE. 